\section{Gene transfer utilizing pollen-tubes of Albuca nelsonii and Tulbaghia violacea}

\author{
Aloka Kumari ${ }^{1}$, Ponnusamy Baskaran ${ }^{1}$ and Johannes Van Staden ${ }^{1 *}$
}

\begin{abstract}
Developing a tissue culture-independent genetic transformation system would be an interesting technique for gene transfer in valuable medicinal and horticultural plants. Efficient gene delivery (Agrobacterium tumefaciens strain LBA 4404: harbouring PBI121 plasmid) was achieved with Km-resistant pollen grains (pollen tube technique) and were found to be GUS-positive for Albuca nelsonii (31.3\%) and Tulbaghia violacea (32.6\%). The Km-resistance (95.6\% for A. nelsonii and $86.7 \%$ for T. violacea) and GUS-positive (100\% for A. nelsonii and $97.5 \%$ for $T$. violacea) putative transgenic seedlings in vitro were obtained with $200 \mathrm{mg} \mathrm{L}^{-1} \mathrm{Km}$. The in vitro plants were obtained from leaf explants of putative transgenic seedlings and were confirmed to be Km-resistant and GUSpositive (T. violacea, $73.7 \%$ and A. nelsonii, $80.5 \%$ ). The plants were successfully acclimatized in the greenhouse. We describe a tissue culture-independent gene transfer technique with high efficiency clonal transgenic plant production for A. nelsonii and T. violacea. This can also be applied to biotechnological crop improvement of the same species and potentially to other plants.
\end{abstract}

Key words: Agrobacterium tumefaciens, genetic transformation, GUS-expression, in vitro regeneration, pollen transformation.

\section{INTRODUCTION}

Tulbaghia violacea (Alliaceae), commonly known as wild garlic, is cultivated for both ornamental and medicinal use (Reinten et al. 2011). It is a clumpforming perennial with narrow leaves, and produces a large cluster of fragrant, violet flowers from mid-summer to autumn (Harvey 1837). T. violacea produces various bioactive compounds and is used to treat earache, fever, high blood pressure, heart problems, chest complaints, high cholesterol, constipation, rheumatism and paralysis (Watt and Breyer-Brandwijk 1962). Similarly, Albuca nelsonii (Hyacinthaceae) is a perennial ornamental and traditional medicinal plant, which is commonly known as Nelson's slime lily (Ascough and Van Staden 2010). The species flowers during September to November. The medicinal and ornamental value of $T$. violacea and $A$. nelsonii suggests their use in studies of pollen transformation as bulbous model plants to obtain a higher efficacy of gene transfer.

Many tissue culture and genetic transformation techniques have been developed to create genetically engineered plants that can tolerate environmental stress, and improve productivity and quality of plant species (Tu et al. 2005, García-Sogo et al. 2010, Eapen 2011, Alikina et al. 2016; Souza et al. 2017). However, the efficiency of current gene transfer techniques are still low, judged
Crop Breeding and Applied Biotechnology 17: 228-234, 2017 Brazilian Society of Plant Breeding. Printed in Brazil http://dx.doi.org/10.1590/198470332017v17n3a35
*Corresponding author: E-mail: rcpgd@ukzn.ac.za

Received: 11 July 2016 Accepted: 06 March 2017

\footnotetext{
${ }^{1}$ University of KwaZulu-Natal Pietermaritzburg, Research Centre for Plant Growth and Development, School of Life Sciences, Scottsville 3209, South Africa,
} 
by the difficulties in recovering fertile transgenic plants and time constraints (Saunders and Matthews 1995, Koetle et al. 2017). A need to find more efficacious and economical methods led to the development of novel alternative systems for genetic transformation that exclude tissue culture steps and rely on simple and inexpensive protocols. Pollen is an important agent for gene transfer to produce transgenic seeds directly through fertilization (Shivanna and Sawhney 2005, Eapen 2011). Pollen has been manipulated by pollen development and function, including alteration of its genome, for the production and improvement of crops and related products.

Pollen transformation is an attractive approach and helps in optimization of crop yield, hybrid seed production and crop improvement in economic plant species (Shivanna and Sawhney 2005). This is a promising research area for obtaining transgenic plants faster and easier than previous procedures (Saunders and Matthews 1995). Accordingly, the direct transformation of pollen grains could help provide an effective alternative to routine transformation methods practiced at present. The technique affords an inexpensive tissue culture-independent production of genetically uniform progeny preventing somaclonal variation. The technique is also genotype independent and applicable in both monocotyledonous and dicotyledonous plants through the regular fertilization process. Pollen transformation using pollen as a "super vector" was proposed earlier (Hess 1987). However, a routine method for pollen transformation is still lacking (Loguercio et al. 1994, Hudson et al. 2001, Eapen 2011, Han et al. 2015). Studies on selection of transformed pollen for the expression of genes are important in recombinant DNA technology, which is a major challenge for production of higher efficiency of transgenic plants. Accordingly, in the present investigation, we aimed to develop a potential alternative gene transfer technique for production of high efficiency clonal transgenic plants, A. nelsonii and T. violacea, by selection of transformed pollen via the pollen tube route. In addition, in vitro transgenic plantlets through leaf explants of putative transgenic seedlings were also established to confirm putative transgenics in vitro, as well as for independent Agrobacteriummediated transformation with large-scale transgenic plant production. The techniques would contribute to modern agriculture systems including breeding and agronomic interests, as well as commercial production to improve specific plant traits with the ability to control biosafety and limit time constraints.

\section{MATERIAL AND METHODS}

\section{Plant material and pollen transformation}

Flowers (before anthesis) of Albuca nelsonii and Tulbaghia violacea were collected from the Botanical Garden of the University of KwaZulu-Natal (lat $29^{\circ} 37.500 \mathrm{~S}$, long $30^{\circ} 24.230 \mathrm{E}$ ), Pietermaritzburg, South Africa, between 07:00 $\mathrm{h}$ and 07:30 $\mathrm{h}$ in the morning. Inflorescences were placed in conical flasks containing tap water and kept at growth room temperature $\left(25 \pm 2{ }^{\circ} \mathrm{C}\right)$ for $30 \mathrm{~min}$. Fresh pollen grains were collected from each inflorescence after dehiscence of the anther. The BWK (Brewbaker and Kwack's 1963) medium containing $10 \%$ sucrose solution, $100 \mathrm{mg} \mathrm{L}^{-1}$ boric acid, $300 \mathrm{mg}$ $\mathrm{L}^{-1}$ calcium nitrate, $100 \mathrm{mg} \mathrm{L}^{-1}$ potassium nitrate and $200 \mathrm{mg} \mathrm{L}^{-1}$ magnesium sulphate (Shivanna and Rangaswamy 1992) was used for control and transformation studies. The fresh pollen grains ( $1 \mathrm{mg}$ ) were placed in BWK medium (1 mL) containing different concentrations $\left(100,200,300,400,500,600\right.$ and $\left.700 \mathrm{mg} \mathrm{mL}^{-1}\right)$ of kanamycin (Km) to select optimal $\mathrm{Km}$ concentration for inhibition of pollen tube growth for selection medium in transformation studies. Agrobacterium tumefaciens [LBA4404, harbouring the binary plasmid vector pCAMBIA1301, with the T-DNA region consisting of GUS gene driven by the Cauliflower Mosaic Virus 35S (CaMV35S) promoter] was grown on a shaker (100 rpm at $25 \pm 2{ }^{\circ} \mathrm{C}$ in the dark) overnight in Luria-Bertani (LB) medium consisting of $0.1 \mathrm{mg} \mathrm{mL}^{-1}$ kanamycin, $0.15 \mathrm{mg} \mathrm{mL}^{-1}$ rifampicin and $50 \mu \mathrm{M}$ acetosyringone. The pellet was collected at $5000 \mathrm{rpm}$ by centrifugation for $20 \mathrm{~min}$ and resuspended in BWK medium consisting of $50 \mu \mathrm{M}$ acetosyringone with $\mathrm{OD} 600=0.5$ density. For transformation study, $1 \mathrm{mg}$ fresh pollen grains were inoculated onto $1 \mathrm{~mL}$ of BWK medium containing $A$. tumefaciens for 30 min under dark condition at $25 \pm 2{ }^{\circ} \mathrm{C}$ for germination before being transferred to selection medium (BWK plus $200 \mathrm{mg} \mathrm{L}^{-1} \mathrm{Km}$ for T. violacea and $600 \mathrm{mg} \mathrm{L}^{-1} \mathrm{Km}$ for $A$. nelsonii) for $15 \mathrm{~min}$. Fresh pollen grains $(1 \mathrm{mg})$ cultured with BWK medium or BWK medium plus $A$. tumefaciens $(1 \mathrm{~mL})$ were used as controls to compare selection treatments. The GUS-positive pollen grains were verified under a light microscope. The pollen slurry $(5-10 \mu \mathrm{L})$ was dropped evenly with the help of a micropipette $(5 \mathrm{ml}$ tip used without damaging the pollen tubes) onto the stigmata of emasculated flowers. Flowers were then rebagged for seed setting. The seeds were set in flowers of bagged natural (non-treated) and treated pollen grains after 8 weeks. Seeds were then collected to determine percentage of seed setting and assays for confirmation of putative transgenic plants. Seeds from both natural and treated pollen grains were sterilized with $0.2 \% \mathrm{HgCl}_{2}$ for $10 \mathrm{~min}$, followed by five washes with sterile 


\section{A Kumari et al.}

distilled water. The seeds were inoculated onto petri dishes containing two layers of Whatman No. 1 filter paper and moistened with $200 \mathrm{mg} \mathrm{L}^{-1} \mathrm{Km}$. The cultures were maintained at a temperature of $25 \pm 2 \circ \mathrm{C}$ and light intensity of 40 $\mu \mathrm{moL} \mathrm{m} \mathrm{m}^{-2} \mathrm{~s}^{-1}$ provided by cool white fluorescent light (OSRAM L $58 \mathrm{~W} / 740$, South Africa) with a $16 \mathrm{~h}$ photoperiod. The efficiency (\%) of $\mathrm{Km}$-resistant seedling was calculated as the number of $\mathrm{Km}$-resistant/total number of seeds inoculated $\times 100$. The Km-resistant plants were used for histochemical GUS assay.

\section{Development and confirmation of putative transgenic plantlet in vitro}

Leaf explants were excised from 20-day-old in vitro germinated putative transgenic and non-transformed (control) seedlings for in vitro regeneration studies. Explants were cultured on MS (Murashige and Skoog 1962) medium containing $30 \mathrm{~g} \mathrm{~L}^{-1}$ sucrose, $8 \mathrm{~g} \mathrm{~L}^{-1}$ agar and supplemented with different combinations and concentrations of plant growth regulators [PGRs: benzyladenine (BA), meta-topolin riboside ( $m T R$ ), thidiazuron (TDZ) and naphthaleneacetic acid (NAA)] for direct shoot regeneration over a period of 8 weeks. Media devoid of PGRs and shoots regenerated with $10 \mu \mathrm{M}$ BA plus $0.5 \mu \mathrm{M}$ NAA from leaf explants of non-transformed seedlings were used as controls. The shoots from respective shoot regeneration medium were cultured onto MS medium with $5 \mu \mathrm{M}$ indole-3-butyricacid (IBA) or indole-3-acetic acid (IAA) plus $25 \mathrm{mg} \mathrm{L}^{-1} \mathrm{Km}$ for rooting and selection of putative transformed shoots for 6 weeks. The combinations of PGRs are indicated in Table 2. The Km-resistant plantlets were used for histochemical GUS assay. The chemicals used in the preparation of the MS medium and PGRs were of analytical grade (Biolab, South Africa; Oxoid, England and Sigma, USA). All media were adjusted to $\mathrm{pH} 5.8$ with $0.1 \mathrm{~N} \mathrm{NaOH}$ before gelling with $8 \mathrm{~g} \mathrm{~L}^{-1}$ agar and autoclaved at $121^{\circ} \mathrm{C}$ for $20 \mathrm{~min}$. The cultures were maintained under $16 \mathrm{~h}$ photoperiod supplied by cool white fluorescent light $\left[40 \mathrm{~mol} \mathrm{~m}^{-2} \mathrm{~s}^{-1}\right.$ photosynthetic photon flux (PPF), OSRAM L $58 \mathrm{~W} / 740$, South Africa] at $25 \pm 2{ }^{\circ} \mathrm{C}$.

The putative transgenic plantlets (Km-resistant plus GUS-positive) were harvested and then transferred to terracotta pots $(95 \times 120 \mathrm{~mm})$ containing a 1:1 (v/v) vermiculite:soil mixture and irrigated with tap water every third day. These plantlets were maintained in the greenhouse $\left(25 \pm 2{ }^{\circ} \mathrm{C}\right.$ under natural photoperiod conditions and midday PPF of 950 $\pm 50 \mathrm{~mol} \mathrm{~m}^{-2} \mathrm{~s}^{-1}$ ) for acclimatization.

\section{Frequency of gene transfer by GUS assay}

The plant materials (leaf tissues and plantlets) from Km-resistant and controls from in vitro germinated seedlings and plantlets, and one-year-old greenhouse-grown plants were used for GUS assay. The X-Gluc solutions and procedure for histochemical GUS assay was performed using $\beta$-Glucuronidase Reporter Gene Staining Kit (Sigma-Aldrich ${ }^{\circ}$, St. Louis, USA). The X-Gluc solutions containing plant materials were incubated at $37^{\circ} \mathrm{C}$ for $24 \mathrm{~h}$, followed by destaining with ethanol for $3 \mathrm{~h}$ to remove chlorophyll. The plant materials were then stored in $70 \%$ ethanol. The efficiency (\%) of GUS expression was calculated as number of plants expressing GUS-positive/total number of plants evaluated $\times 100$.

\section{Statistical analysis}

All experiments were conducted three times with 25 replicates for each treatment for pollen transformation, seed germination, shoot regeneration, rooting and GUS assay. Data were analyzed using a one-way analysis of variance (ANOVA), and are presented as means \pm standard error. Treatment means were separated using Duncan's multiple range tests at the $5 \%$ probability level and analyzed using IBM SPSS for Windows version 23 (SPSS Inc., Chicago, IL, USA). Percentage data were arcsine square root transformed before using an analysis of variance.

\section{RESULTS AND DISCUSSION}

\section{Gene delivery by pollen transformation}

Pollen grains were inoculated on BWK medium with different concentrations of $\mathrm{Km}$ to investigate the optimal

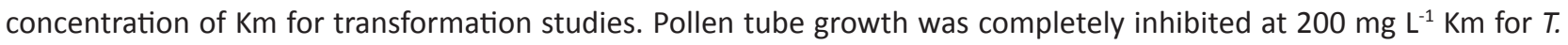
violacea and $600 \mathrm{mg} \mathrm{L}^{-1} \mathrm{Km}$ for $A$. nelsonii except the controls (Figure 1A, B, C, D). This would allow for efficient gene delivery via the pollen tube pathway. Optimization of $\mathrm{Km}$ concentration is essential for effective genetic transformation and has been reported with different methods in other plant species (Bino et al. 1987, Baskaran and Dasgupta 2012). A selection of $\mathrm{Km}$ concentration ( $200-400 \mathrm{mg} \mathrm{L}^{-1}$ ) has been reported with less sensitive and longer pollen tube growth 
for chimaeric tomato (Bino et al. 1987). In this study, pollen germination was observed in all treatments in both plant species (Table 1). However, GUS-positive pollen tube growth varied significantly between BWK medium plus $A$. tumefaciens and BWK medium plus A. tumefaciens and Km (selection) treatments (Table 1). Frequency of GUS-positive pollen germination was $32.6 \%$ for T. violacea and $31.3 \%$ for $A$. nelsonii during the selection treatment (Table 1 and Figure 1E, F). The control (pollen germination with BWK medium) treatment did not show GUS-positive germination of pollen (Table 1). This indicates that successful gene delivery to the pollen could be assessed by histochemical GUS assay. Germinated pollen from all treatments was applied gently on the stigmata of emasculated flowers for seed setting. The

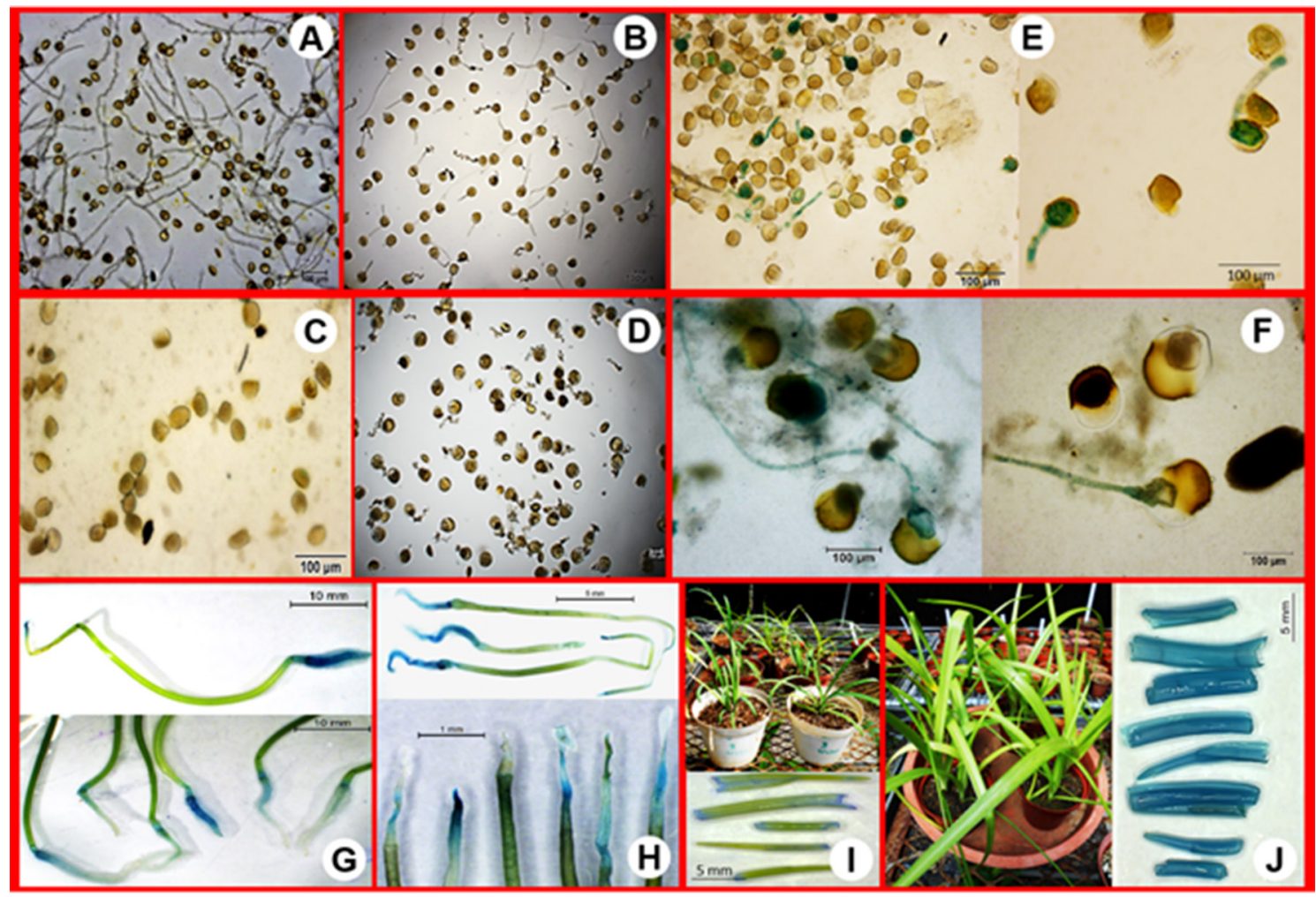

Figure 1. Pollen tube growth and GUS-positive expression in pollen and seedlings of $T$. violacea and $A$. nelsonii: Pollen tube growth in BWK medium for T. violacea (A) and A. nelsonii(B); Inhibition of pollen tube growth at Km for T. violacea (C) and $A$. nelsonii (D); GUS-positive pollen germination of $T$. violacea $(\mathbf{E})$ and $A$. nelsonii(F);GUS-positive seedlings of $T$. violacea $(\mathbf{G})$ and $A$. nelsonii $(\mathbf{H})$; The GUS-expression of leaf in one-year-old greenhouse-grown plants of $T$. violacea(I) and $A$. nelsonii (J).Bar $A-F 100 \mu \mathrm{m} ; H$ 1mm and 5 $\mathrm{mm}$; and $l, J 5 \mathrm{~mm}$.

Table 1. Development of putative transgenic pollen and seedlings by incubation of Agrobacterium tumefaciens for T. violacea and A. nelsonii

\begin{tabular}{|c|c|c|c|c|c|c|}
\hline Plant name & Treatments & $\begin{array}{c}\text { GUS +ve } \\
\text { Pollen (\%) }\end{array}$ & $\begin{array}{c}\text { Seed setting } \\
(\%)\end{array}$ & $\begin{array}{l}\text { Km-resistant } \\
\text { Seedlings (\%) }\end{array}$ & $\begin{array}{c}\text { GUS }{ }^{\text {+ve }} \\
\text { Km-resistant } \\
\text { Seedlings (\%) }\end{array}$ & $\begin{array}{c}\text { GUS +ve } \\
\text { greenhouse- } \\
\text { grown plants (\%) }\end{array}$ \\
\hline Tulbaghia violacea & $\begin{array}{c}\text { Natural plant (control) } \\
\text { BWK (control) } \\
\text { BWK + Agro (control) } \\
\text { BWK + Agro }+\mathrm{Km}\end{array}$ & $\begin{array}{c}0 \\
0 \\
35.9 \pm 1.06 \mathrm{a} \\
32.6 \pm 1.48 \mathrm{~b}\end{array}$ & $\begin{array}{l}85.5 \pm 0.24 a \\
62.5 \pm 0.67 b \\
28.2 \pm 1.28 c \\
24.8 \pm 1.02 d\end{array}$ & $\begin{array}{c}0 \\
0 \\
63.1 \pm 0.56 \mathrm{~b} \\
86.7 \pm 0.27 \mathrm{a}\end{array}$ & $\begin{array}{c}0 \\
0 \\
90.0 \pm 0.28 \mathrm{~b} \\
97.5 \pm 0.12 \mathrm{a}\end{array}$ & $\begin{array}{c}0 \\
0 \\
25.5 \pm 0.12 b \\
41.6 \pm 0.18 a\end{array}$ \\
\hline Albuca nelsonii & $\begin{array}{c}\text { Natural plant (control) } \\
\text { BWK (control) } \\
\text { BWK + Agro (control) } \\
\text { BWK + Agro }+\mathrm{Km}\end{array}$ & $\begin{array}{c}0 \\
0 \\
42.3 \pm 0.87 \mathrm{a} \\
31.3 \pm 0.42 \mathrm{~b}\end{array}$ & $\begin{array}{l}82.6 \pm 0.27 \mathrm{a} \\
80.0 \pm 0.42 \mathrm{~b} \\
77.2 \pm 1.08 \mathrm{c} \\
74.7 \pm 0.72 \mathrm{~d}\end{array}$ & $\begin{array}{c}0 \\
0 \\
83.3 \pm 0.32 b \\
95.6 \pm 0.24 a\end{array}$ & $\begin{array}{c}0 \\
0 \\
91.7 \pm 0.46 b \\
100 a\end{array}$ & $\begin{array}{c}0 \\
0 \\
33.3 \pm 0.20 \mathrm{~b} \\
50.0 \pm 0.26 \mathrm{a}\end{array}$ \\
\hline
\end{tabular}

Values are mean \pm standard error (SE). Values followed by different letters indicate significant difference between means ( $p=0.05)$; comparison by DMRT. Greenhouse grown 12-months-old plants. Km, kanamycin. 
seed setting varied between natural and treated pollen grains. However, setting was $24.8 \%$ for $T$. violacea and $74.7 \%$ for $A$. nelsonii in the selection treatment, signifying that $\mathrm{Km}$-resistant pollen effected seed setting, while the efficiency varied between species (Table 1). Direct application of plasmid solution or A. tumefaciens containing reporter genes on stigmas or styles has been observed with lack of seed setting in other plant species (Shou et al. 2002, Han et al. 2015). Therefore, $\mathrm{Km}$ selection in pollen tube growth is important for transformation when using pollen tubes. The results of the present study revealed that pollen transformation by $\mathrm{Km}$ selection is an effective technique for improved and rapid gene transfer in $T$. violacea and $A$. nelsonii.

\section{Selection of Km-resistant and GUS confirmation}

$\mathrm{Km}$-resistant seedlings were screened under in vitro conditions. Germination of the seeds produced from control experiments (natural plant and pollen grains germinated in BWK medium) was completely inhibited after 3 weeks of culture. $\mathrm{Km}$-resistant seedlings were observed in both $A$. tumefaciens alone or A. tumefaciens plus Km-treated pollen produced seeds. However, seeds produced from $A$. tumefaciens plus $\mathrm{Km}$-treated pollen exhibited significantly improved $\mathrm{Km}$-resistance $(86.7 \%$ for T. violacea and $95.6 \%$ for $A$. nelsonii) and GUS-positive (97.5\% for T. violacea and $100 \%$ in $A$. nelsonii) seedlings (Table 1 and Figure 1G, H). Effectiveness of Km selection and GUS expression for production of putative transgenic plants in different methods has been reported for other plant species (Bino et al. 1987, Twell et al. 1990, Baskaran and Dasgupta 2012, Baskaran et al. 2016, Koetle et al. 2017, Souza et al. 2017). GUS-positive seedlings were successfully acclimatized with 1:1 (v/v) vermiculite:soil mixture in the greenhouse. The GUS-expression with different frequency was exhibited from leaf tissues of oneyear-old greenhouse-grown plants (Table 1 and Figure 1I, J). This result suggests that high efficiency of gene transfer via the pollen tube pathway is possible for the improvement of ornamental and medicinal $T$. violacea and $A$. nelsonii.

\section{Transgenic plant production in vitro}

Shoots were induced at the cut edges of leaf explants from all treatments, except the control (Table 2). Among the different PGR combinations, MS medium containing $10 \mu \mathrm{M}$ BA plus $0.5 \mu \mathrm{M}$ NAA and $10 \mu \mathrm{M}$ TDZ plus $0.5 \mu \mathrm{M}$ NAA combinations produced significantly higher numbers of shoots for $T$. violacea and $A$. nelsonii respectively (Table 2 and Figure $2 A, B$ ). The results strongly indicated that PGR combination for shoot regeneration is genotype/speciesdependent as reported earlier (Narasimhulu and Chopra 1988, Steinitz et al. 2006, Ascough and Van Staden 2010). The shoots were rooted with IBA or IAA and Km treatments (Table 2 and Figure $2 \mathrm{C}, \mathrm{D}$ ). Rooting was lower in controls (Table 2). The rooted plantlets from control treatments died after 8 weeks of culture (Figure 2E, F). This indicates that the plantlets are susceptible to

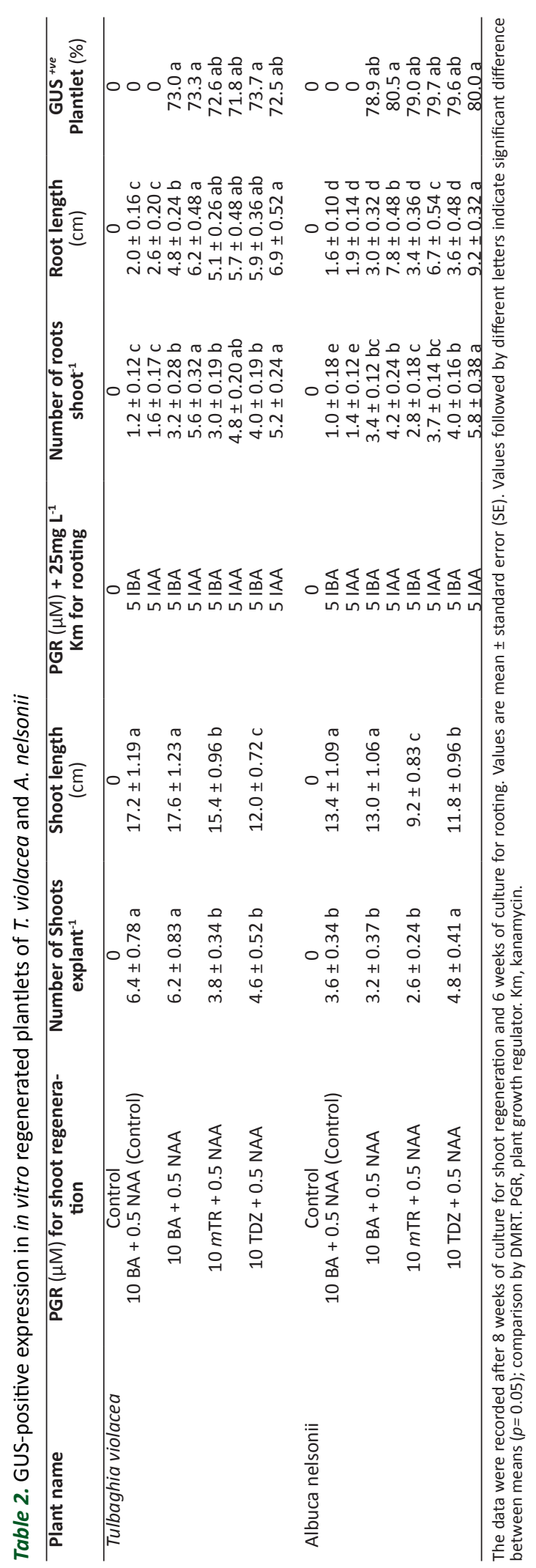




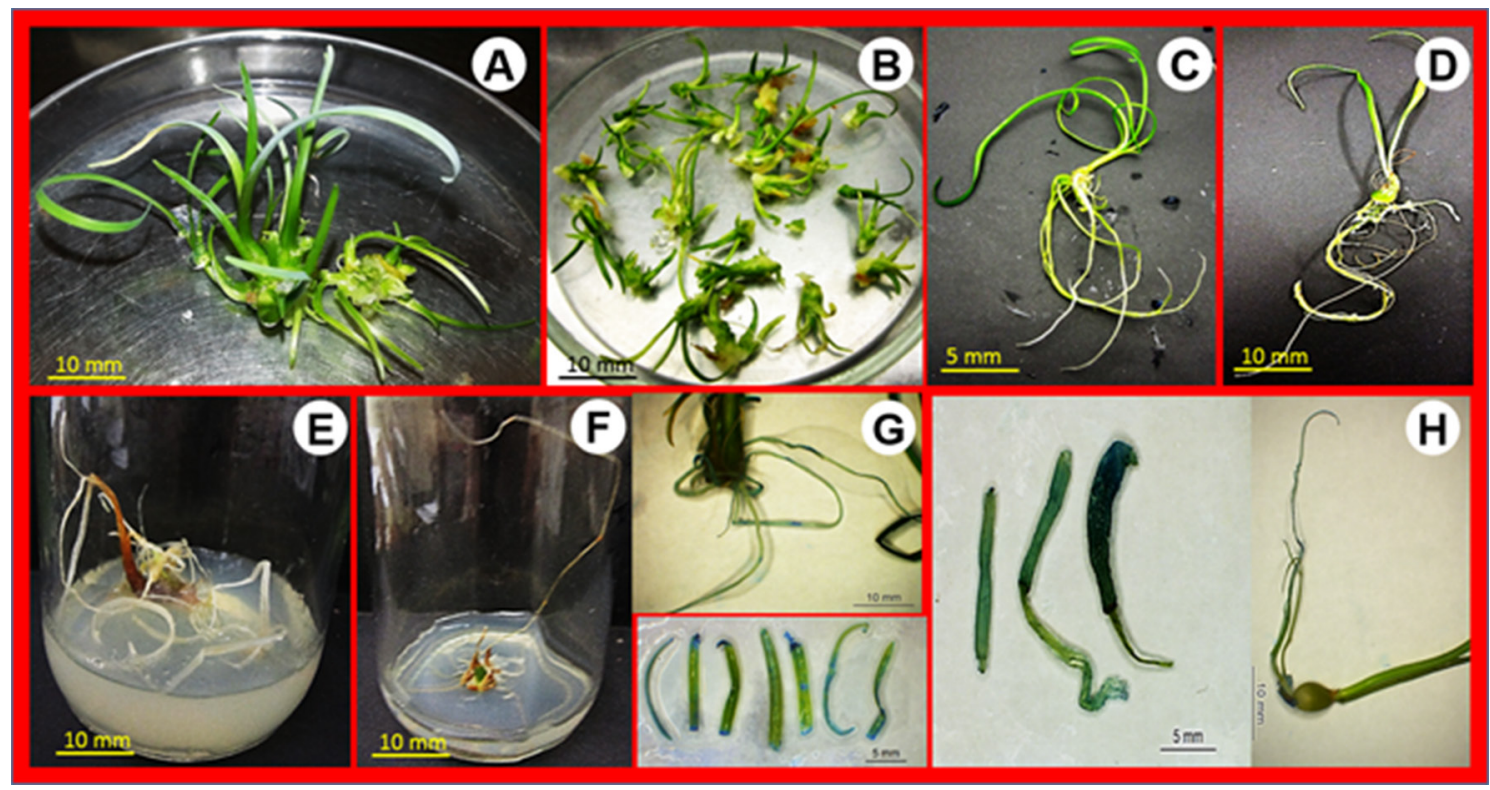

Figure 2. In vitro regeneration and GUS-positive expression of $T$. violacea and $A$. nelsonii. Formation of multiple shoots from $10 \mu M$ BA $+0.5 \mu \mathrm{M}$ NAA for T. violacea (A) and $10 \mu \mathrm{M}$ TDZ + $0.5 \mu \mathrm{M}$ NAA for A. nelsonii (B); Rooting of shoots in T. violacea (C) and A. nelsonii (D);Necrosed plantlets of $T$. violacea $(\mathbf{E})$ and $A$. nelsonii $(\mathbf{F})$ in control treatments; The GUS-expression from Km-resistant plantlets of T. violacea (G) and $A$. nelsonii (H).Bar $A, B, D, E, F 10 \mathrm{~mm} ; C, 5 \mathrm{~mm} ; G 10 \mathrm{~mm}$ and $5 \mathrm{~mm}$; and $H 5 \mathrm{~mm}$ and $10 \mathrm{~mm}$.

$\mathrm{Km}$. Rooting rate was dependent on auxin and respective shoot regeneration treatments (Table 2). The Km-resistant plantlets showed transient GUS expression in all treatments, except the control (Table 2 and Figure 2G, H). The frequency of GUS expression varied between T. violacea and A. nelsonii, however, frequency of GUS-positive plantlets were not significantly different within the same species. Therefore, the results confirmed that in vitro Km-resistant putative transgenic plantlets could be achieved from leaf explants of putative transgenic seedlings for large-scale transgenics production without Agrobacterium-mediated transformation.

\section{CONCLUSIONS}

The present investigation was successful with higher efficiency of pollen gene transfer using kanamycin selection in valuable ornamental and medicinal plants, $T$. violacea and $A$. nelsonii. This method reduces false positives and chimeric plants by careful pollen selection, infection conditions and optimal $\mathrm{Km}$ concentration. This protocol has great potential for large-scale clonal transgenic plant production and commercial application of production of novel genotypes. The presented system could be adopted for temperature sensitivity and self-incompatibility of other plant species; however, the progeny needs to be screened in order to confirm genetic stability of transgenics. The in vitro putative transgenic plantlets through direct organogenesis were established with leaf explants of transformed seedlings and were confirmed by GUS-positive expression. Developed in vitro regeneration protocol has advantageous for independent-Agrobacteriummediated transformation with large-scale transgenic plant production.

\section{ACKNOWLEDGEMENTS}

Financial support by the University of KwaZulu-Natal (UKZN), Pietermaritzburg is gratefully acknowledged. The authors are grateful to the Microscopy and Microanalysis Unit (MMU), UKZN, Pietermaritzburg for microscopic assistance. 


\section{REFERENCES}

Alikina O, Chernobrovkina M, Dolgov S and Miroshnichenko D (2016) Tissue culture efficiency of wheat species with different genomic formulas. Crop Breeding and Applied Biotechnology 16: 307-314.

Ascough GD and Van Staden J (2010) Micropropagation of Albuca bracteata and $A$. nelsonni - Indigenous ornamentals with medicinal value. South African Journal of Botany 76: 579-584.

Baskaran P and Dasgupta I (2012) Gene delivery using microinjection of agrobacterium to embryonic shoot apical meristem of elite indica rice cultivars. Journal of Plant Biochemistry and Biotechnology 21: $268-274$.

Baskaran P, Soós V, Balázs E and Van Staden J (2016) Shoot apical meristem injection: a novel and efficient method to obtain transformed cucumber plants. South African Journal of Botany 103: 210-215.

Bino RJ, Hille J and Franken J (1987) Kanamycin resistance during in vitro development of pollen from transgenic tomato plants. Plant Cell Reports 6: 333-336.

Brewbaker JL and Kwack BH (1963) The essential role of calcium ions in pollen germination and pollen tube growth. American Journal of Botany 50: 859-865.

Eapen S (2011) Pollen grains as a target for introduction of foreign genes into plants: an assessment. Physiology and Molecular Biology of Plants 17: 1-8.

García-Sogo B, Pineda B, Castelblanque L, Antón T, Medina M, Roque E, Torresi C, Beltrán JP, Moreno V and Cañas LA (2010) Efficient transformation of Kalanchoe blossfeldiana and production of malesterile plants by engineered anther ablation. Plant Cell Reports 29: 61-77.

Han LW, Ge Y, Yao L, Cui CS and Qu SP (2015) Transformation of soft rot resistant aiiA gene into Chinese cabbage (Brassica rapa ssp. pekinensis) by the pollen-tube pathway. International Journal of Agriculture and Biology 17: 407-409.

Harvey WH (1837) Tulbaghia violacea. Botanical Magazine 64: t. 3555

Hess D (1987) Pollen-based techniques in genetic manipulation. International Review of Cytology 107: 367-395.

Hudson LC, Chamberlain D and Stewart JR (2001) GFP-tagged pollen to monitor pollen flow of transgenic plants. Molecular Ecology Notes 1: 321-324.

Koetle MJ, Baskaran P, Finnie JF, Soos V, Balázs E and Van Stadena J (2017) Optimization of transient GUS expression of Agrobacterium-mediated transformation in Dierama erectum Hilliard using sonication and Agrobacterium. South African Journal of Botany 111: 307-312.
Loguercio LL, Termignoni RR and Ozaki LS (1994) The reversible inhibition of pollen germination of Nicotiana tabacum L. - An entry into a transformation system. Plant Cell Reports 13: 231-236.

Murashige T and Skoog F (1962) A revised medium for rapid growth and bio assays with tobacco tissue cultures. Physiologia Plantarum 15: 473-497.

Narasimhulu SB and Chopra VL (1988) Species specific shoot regeneration response of cotyledonary explants of Brassicas. Plant Cell Reports 7: 104-106.

Reinten EY, Coetzee JH and Van Wyk B-E (2011) The potential of South African indigenous plants for the international cut flower trade. South African Journal of Botany 77: 934-946.

Saunders JA and Matthews BF (1995) Pollen transformation in tobacco: Pollen electro- transformation methods in molecular biology, plant cell electroporation and electrofusion protocols. JA Nickoloff Humana Press Inc., Totowa, 81p.

Shivanna KR and Rangaswamy NS (1992) Pollen biology: a laboratory manual. Springer Berlin, Germany, 119p.

Shivanna KR and Sawhney VK (2005) Pollen biotechnology for crop production and improvement. Cambridge University Press, New York, 261p.

Shou H, Palmer RG and Wang K (2002) Irreproducibility of the soybean pollen-tube pathway transformation procedure. Plant Molecular Biology Reporter 20: 325-334.

Souza RAV, Alves MC, Carneiro NP, Barros BA, Borém A and Carneiro AA (2017) Agrobacterium-mediated genetic transformation of a tropical elite maize line. Crop Breeding and Applied Biotechnology 17: 133-140.

Steinitz B, Amitay A, Gaba V, Tabib Y, Keller M and Levin I (2006) A simple plant regeneration-ability assay in a range of Lycopersicon species. Plant Cell Tissue and Organ Culture 84: 269-278.

Tu S, Sangwan RS, Raghavan V, Verma DPS and Sangwan-Norreel BS (2005) Transformation of pollen embryo-derived explants by Agrobacterium tumefaciens in Hyoscyamus niger. Plant Cell Tissue and Organ Culture 81: 139-148.

Twell D, Yamaguchi J and McCormick S (1990) Pollen-specific gene expression in transgenic plants: coordinate regulation of two different tomato gene promoters during microsporogenesis. Development 109: 705-713.

Watt JM and Breyer-Brandwijk MG (1962) The medicinal and poisonous plants of southern and eastern Africa. $2^{\text {nd }}$ edn., Livingstone, London, $1457 p$. 